\title{
IJRETINA
}

Intemational Joumal of Reting

\section{VALIDATION OF WINROP ALGORITHM AS A SCREENING TOOL FOR RETINOPATHY OF PREMATURITY IN A NORTHERN SPANISH COHORT OF PRETERM INFANTS}

\author{
Raúl Fernández-Ramón*, María Dolores Ruiz-Sancho, Isora Follana-Neira \\ Department of Ophthalmology, Hospital Universitario Marqués de Valdecilla, Santander, Spain.
}

\begin{abstract}
Introduction: WINROP (Weight, Insulin-like growth factor 1, Neonatal Retinopathy of Prematurity) is a computer-based ROP risk which correlate postnatal weight gain with the developed of treatment-requiring ROP. The purpose of this study was to evaluate the ability of the WINROP algorithm to detect severe (Type 1 or Type 2) ROP in a Spanish cohort of infants.
\end{abstract}

Methods: Birth weight, gestational age, and weekly weight measurements of preterm infants (>23 and $<32$ weeks gestation) born between 2015 and 2017 were retrospectively collected and entered in WINROP algorithm. Infants were classified according alarm activation and compared with ROP screening outcomes. Sensitivity, specificity, and predictive values were calculated.

Result: $A$ total of 109 infants were entered into the analysis. The mean gestational age was $29.37 \pm$ 2.26 weeks and mean birth weight was $1178 \pm 320 \mathrm{~g}$. Alarm occurred in 47.7\% (52/109) of neonates, with a mean time from birth to alarm of $1.9 \pm 1.4$ weeks. WINROP had a sensitivity of $100 \%$ (CI 95\%, 59-100), a specificity of 55.9\% (Cl 95\%, 45.7-65.7), a positive predictive value of 13.5\% (CI 95\%, 11.116.2) and a negative predictive value of $100 \%$ (CI 95\%, 93.7-100) for predicting severe ROP.

Conclusion: The WINROP algorithm has proven to be a useful tool in the detection of severe ROP in our cohort. Nevertheless, in extremely preterm infants (GA <28 weeks) the results should be taken with caution and an optimization of WINROP can be necessary to improve its utility in other populations.

\footnotetext{
Keywords: retinopathy, prematurity, WINROP, weight gain, screening tool

Cite This Article: FERNÁNDEZ-RAMÓN, Raúl. Validation of WINROP algorithm as a screening tool for retinopathy of prematurity in a northern Spanish cohort. International Journal of Retina, [S.I.], v. 4, n. 1, p. 1, feb. 2021. ISSN 2614-8536. Available at: <https://www.ijretina.com/index.php/iiretina/article/view/137>. Date accessed: 22 feb. 2021. doi: https://doi.org/10.35479/ijretina.2021.vol004.iss001.137.
}

${ }^{*}$ Correspondence to: Dr. Raúl Fernández-Ramón, Department of Ophthalmology, Hospital Universitario Marqués de Valdecilla

Santander, Spain,

reulfer@gmail.com

\section{INTRODUCTION}

Retinopathy of prematurity (ROP) is a potentially blinding vasoproliferative disorder affecting premature infants. ${ }^{1}$ Low gestational age (GA), low birth weight (BW), and oxygen supplementation are the main risk factors for developing the disease. ${ }^{2}$ High-quality health care and effective screening program are essential for reducing the incidence of ROP and its visual complications. ${ }^{3}$ The goal of screening program is to detect preterm infants with treatment-demanding ROP among all at-risk infants. ${ }^{4}$ With current screening criteria based on GA and BW, an excessive number of eye examinations, which can be stressful for preterm infants, are performed. ${ }^{5}$ Less than $10 \%$ of screened infants require treatment. ${ }^{4}$ 
Previous studies have demonstrated links between low insulin-growth factor 1 (IGF-1) levels in premature infants, very-low-birth-weight, poor postnatal weight and development of treatmentdemanding ROP. ${ }^{6,7,8}$ The Weight, Insulin-like growth factor 1, Neonatal, Retinopathy Of Prematurity (WINROP) algorithm was developed in Sweden, using weekly weight measurements and serum IGF1 levels to predict the risk of developing severe ROP. ${ }^{9}$ The algorithm was later modified to use only weekly weight gain. ${ }^{10}$

Several studies have evaluated the efficacy of WINROP algorithm with varying results. ${ }^{10,11,12,13}$ The aim of this study is to validate the WINROP in a northern Spanish cohort of preterm infants.

\section{METHODS}

A retrospective evaluation of the WINROP algorithm was performed using data from preterm infants undergoing ROP screening at the Marques de Valdecilla University Hospital, Santander, Spain, between 2015 and 2017. The study was executed in compliance with the tenets of the Declaration of Helsinki and ethical approval was taken from hospital Ethical committee.

According the WINROP requirements, infants with a GA $>23$ and $<32$ weeks at birth, weekly weight measurements, and physiological weight gain of $<450 \mathrm{~g} /$ week were included in this study. Patients with weight gain from non-physiological causes, such as hydrocephalus, excessive edema, or ascites; were excluded. Gestational age was calculated using last menstrual period and supported by ultrasound biometric measurements in the first trimester. Screening criteria used were BW $\leq 1500 \mathrm{~g}, \mathrm{GA} \leq 32$ weeks and/or unstable neonatal clinical course. ROP examinations were started at 4 weeks of birth, by an experienced specialist ophthalmologist. The followup plan was established with an interval of 1 to 3 weeks proposed by the ophthalmologist according with funduscopic findings. The retinopathy was classified according to the International Classification of ROP (ICROP) and the International Classification of the Early Treatment for Retinopathy of Prematurity (ETROP). ${ }^{14,15}$ Severe ROP was defined as Type 1 (stage 1 or 2 in zone I with plus disease, stage 3 in zone I with or without plus disease, or stage 2 or 3 in zone II with plus disease) or Type 2 (stage 1 or 2 in zone I without disease plus or stage 3 in zone II). The rest of stages were included in lowgrade ROP.

GA, BW, and weekly weights were entered into the WINROP website (https://www.winrop.com/) until alarm was signaled or a postmenstrual age of 36 weeks. Infants were categorized as high risk and low risk to develop ROP requiring treatment (Type 1 ROP) depending on alarm activation.

Quantitative variables were presented as mean \pm SD, and qualitative variables as absolute numbers and percentages. The Kolmogorov-Smirnov test was used to analyse the distribution of variables. Comparisons of GA and BW were made considering ROP categories (type 1, type 2, low-grade and no ROP). Kruskal-Wallis and post-hoc tests were used to analyse non-normally distributed variables. A value of $p<0.05$ was considered statistically significant. Sensitivity, specificity, positive and negative predictive values of the algorithm were calculated. 95\% confidence intervals were calculated using exact Clopper-Pearson method. Data were analyzed using SAS software version 9.3 (SAS Institute Inc., Cary, $\mathrm{NC}$ ).

\section{RESULTS}

During study period, 123 infants with a GA $<32$ weeks were screened for ROP. Overall, 12 infants were excluded for the following reasons: 5 died before the final ROP status, 7 had incomplete body weight data and 2 developed hydrocephalus. A total of 109 met the requirements of WINROP and were included in our analytic database. 
The mean GA at birth was $29.37 \pm 2.26$ (range, 25-31.9) weeks and the mean BW was $1178 \pm 320$ (range, 600-1940) g. Statistically significant lower mean GA and BW were observed in more severe type of ROP (Table 1).

Table 1. Birth characteristics and ROP categories

\begin{tabular}{|c|c|c|c|c|c|c|}
\hline & Type 1 ROP & Type 2 ROP & $\begin{array}{l}\text { Low-grade } \\
\text { ROP }\end{array}$ & No ROP & All infants & p-value \\
\hline n (\%) & $3(2.7)$ & $4(3.7)$ & $24(22)$ & 78 (71.6) & $109(100)$ & \\
\hline GA (weeks), mean \pm SD & $25.3 \pm 0.6$ & $27.3 \pm 1.0$ & $27.9 \pm 2.2(25-$ & $30.1 \pm 1.9(26-$ & $29.4 \pm 2.3(25-$ & $<0.001 *$ \\
\hline (range) & $(25-26)$ & $(26-28)$ & 32) & 32) & 32) & \\
\hline BW (g), mean $\pm S D$ & $675 \pm 87$ & $910 \pm 226$ & $950 \pm 233$ & $1278 \pm 291$ & $1175 \pm 319$ & $<0.001 *$ \\
\hline (range) & $(600-750)$ & $(710-1005)$ & $(680-1620)$ & $(680-1940)$ & $(600-1940)$ & \\
\hline
\end{tabular}

BW: Birth weight, GA: Gestational age, ROP: Retinopathy of prematurity

* Kruskal-Wallis test

No grade of ROP developed in $78(71.6 \%)$ of the infants. Of the 31 (28.4\%) patients who developed ROP, 3 (2.7\%) had type 1 ROP, 4 (3.7\%) had type 2 ROP, and 24 (22\%) had low-grade ROP (Table 1). No severe ROP was found among the infants with GA at birth $\geq 29$ weeks and BW $\geq 1500 \mathrm{~g}$. In contrast, $19.2 \%$ of extremely preterm infants (GA $<28$ weeks), $13.9 \%$ of extremely low birth weight (ELBW) infants (BW $<1000 \mathrm{~g}$ ), and $3.6 \%$ of low birth weight (LBW) infants (BW 1000-1499 g) developed severe ROP (Figure 1).

Figure 1. Distribution of infants in different BW and GA subgroups according to the presence and type of ROP

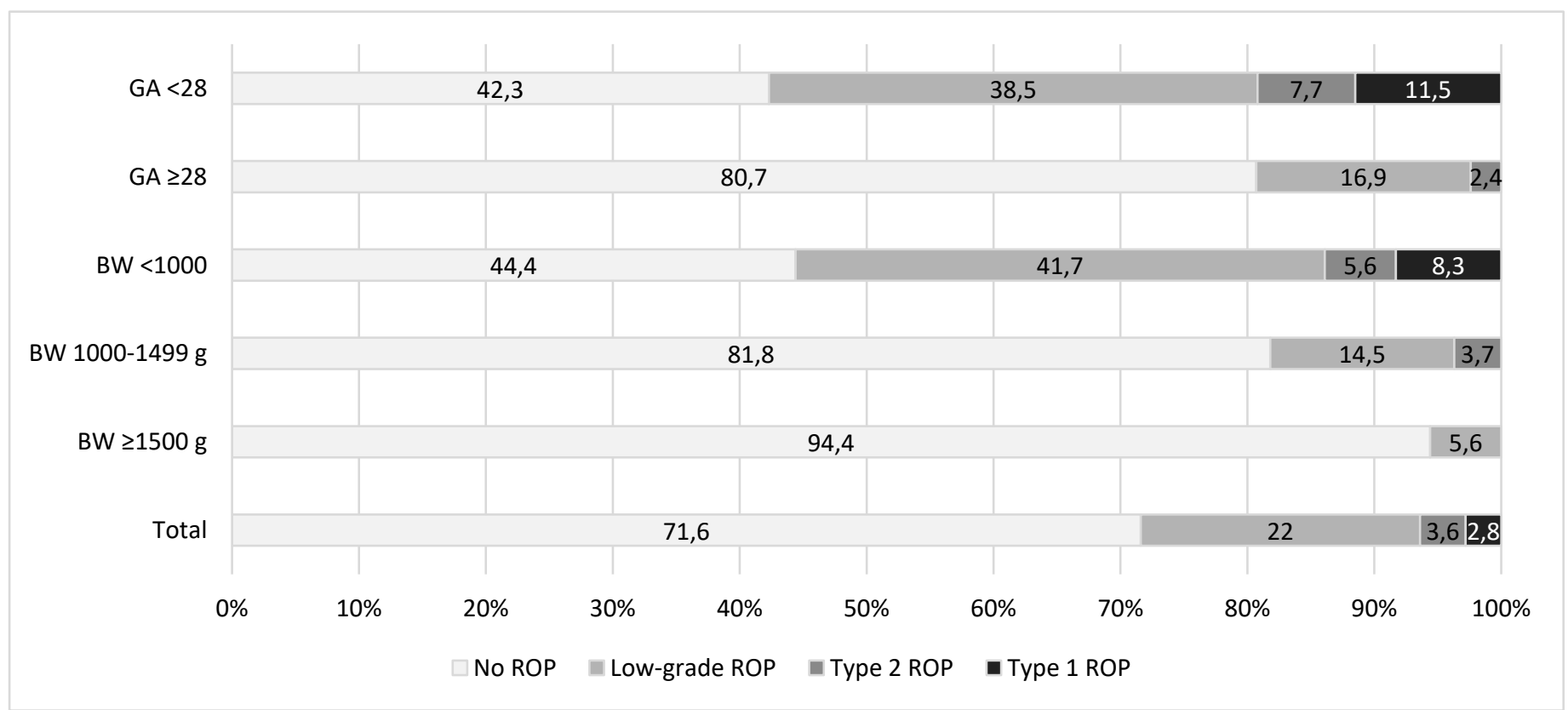


All 3 type 1 ROP infants received intravitreal bevacizumab (Avastin) and 2 of them was treated with laser photocoagulation. The mean time from birth to treatment was $11.3 \pm 1.5$ (range, 10-13) weeks.

WINROP alarm was signaled in 52 neonates (47.7\%) and $100 \%(7 / 7)$ of all infants who developed severe ROP (type 1 and 2). The mean time from birth to alarm was $1.9 \pm 1.4$ (range, $0-6$ ) weeks and the mean GA for alarm was $29.9 \pm 1.7$ (range, 27-32) weeks.
The sensitivity of WINROP algorithm to detect severe ROP in our cohort was $100 \%(\mathrm{Cl} 95 \%, 59-100)$ with a specificity of $55.9 \%$ (Cl 95\%, 45.7-65.7). The positive predictive value (PPV) was 13.5\% (CI 95\%, 11.1-16.2) and the negative predictive value (NPV) was $100 \%$ (Cl 95\%, 93.7-100) (Table 2). These parameters vary according to gestational age, observing a lower specificity in extremely premature and ELBW infants (Table 3).

Table 2. Sensitivity, specificity and predictive values of the WINROP algorithm

\begin{tabular}{lccccc}
\hline & Alarm & No alarm & Total & Sensitivity, \% (95\% Cl) & $\begin{array}{c}\text { Specificity, \% (95\% } \\
\text { Cl) }\end{array}$ \\
\hline $\begin{array}{l}\text { ROP categories, } \mathbf{n} \\
\text { Severe ROP }\end{array}$ & 7 & 0 & 7 & $100(59-100)$ & $55.9(45.7-65.7)$ \\
No severe ROP/ No ROP & 45 & 57 & 102 & \\
$\quad$ Total & 52 & 57 & 109 & \\
Predictive value, \% (95\% Cl) & & & \\
PPV & $13.5(11.1-16.2)$ & & \\
NPV & & $100(93.7-$ \\
\end{tabular}

$\mathrm{Cl}$ : Confidence interval, NPV: Negative predictive value, PPV: Positive predictive value, ROP: Retinopathy of prematurity

Table 3. Diagnostic performance of WINROP algorithm according to GA at birth and BW

\begin{tabular}{|c|c|c|c|c|c|}
\hline & $\begin{array}{l}\text { Number of } \\
\text { infants }\end{array}$ & $\begin{array}{l}\text { Sensitivity, \% } \\
(95 \% \mathrm{Cl})\end{array}$ & $\begin{array}{l}\text { Specificity, \% } \\
(95 \% \mathrm{Cl})\end{array}$ & $\begin{array}{l}\text { PPV, \% (95\% } \\
\text { Cl) }\end{array}$ & $\begin{array}{l}\text { NPV, \% (95\% } \\
\mathrm{Cl})\end{array}$ \\
\hline \multicolumn{6}{|l|}{ Gestational age } \\
\hline \multirow[t]{2}{*}{ EP (< 28 weeks) } & 20 & 100 & 19 & 22.7 & 100 \\
\hline & & $(47.8-100)$ & $(5.4-41.9)$ & $(19.3-26.6)$ & $(39.8-100)$ \\
\hline \multirow[t]{2}{*}{ VP (28-32 weeks) } & 89 & 100 & 64.1 & 6.5 & 100 \\
\hline & & $(15.8-100)$ & $(52.7-74.5)$ & $(4.9-8.5)$ & $(93.2-100)$ \\
\hline \multicolumn{6}{|l|}{ Birth Weight } \\
\hline \multirow[t]{2}{*}{ ELBW (< $1000 \mathrm{~g})$} & 36 & 100 & 16.1 & 16.1 & 100 \\
\hline & & $(47.2-100)$ & $(5.4-33.7)$ & $(14.1-18.3)$ & $(47.8-100)$ \\
\hline \multirow[t]{2}{*}{ VLBW (1000-1499 g) } & 55 & 100 & 62.3 & 9.1 & 100 \\
\hline & & $(15.8-100)$ & $(47.9-75.2)$ & $(6.6-12.4)$ & $(89.4-100)$ \\
\hline
\end{tabular}

CI: Confidence interval, NPV: Negative predictive value, PPV: Positive predictive value, EP: Extremely Preterm, VP: Very Preterm, ELBW: Extremely Low Birth Weight, VLBW: Very Low Birth Weight 


\section{DISCUSSION}

Predictably, incidence and severity of ROP increased with lower GA at birth and BW. In our cohort, $28.4 \%$ and $6.4 \%$ of infants developed any grade of ROP and severe form, respectively. Similarly, other studies have reported incidences of ROP ranging from $9.3 \%$ to $43.1 \%$ and $1.8-11.1 \%$ infants developed severe ROP. ${ }^{16-20}$ Nevertheless, different screening criteria were used.

In the present study, the sensitivity of WINROP algorithm for detecting infants at risk of severe ROP was $100 \%$. All infants requiring or potentially requiring treatment (Type 1 or Type 2 ROP) were correctly identified. Similar results were observed in cohorts from Sweden, the USA and the Czech Republic (Table 4) 10,21,22,23. In contrast, studies from other countries have reported worse data and most of them have shown sensitivity values ranging from $80 \%$ to $90 \% .^{13(23-31)}$ Demographic and neonatal management differences can explain these varying values. WINROP algorithm was created from a Swedish cohort of premature infants. Population similarities with the Nordic country could explain the good results observed in our study and in other countries such as Sweden, the USA, Canada or the Czech Republic. The influence of the quality of care for premature neonates on the WINROP effectiveness is supported on the low number of infants with GA at birth $>28$ weeks who developed severe ROP in the studies with the best algorithm results, including the present one, ${ }^{10(21-23)}$ in contrast with the multiple cases observed in countries with poorer data. ${ }^{21,25,26}$

Low specificity and negative predictive value, especially in the groups of extremely preterm infants (GA <28 weeks) and those with extremely low birth (BW <1000 g), were observed in present study. Poor postnatal weight gain is a frequent problem for extremely preterm infants, and, in consequence, relatively high numbers of false positives were detailed in this group when using WINROP. A reassessment of the WINROP alarm have been proposed to improve the specificity of the algorithm. ${ }^{32}$

According to other studies, most of infants who were incorrectly classified by WINROP as low risk had complicated neonatal courses and/or were born with extreme prematurity (GA <28 weeks) (28)(30)(33). This may be related with the non-inclusion of factors involved in the development of ROP such as oxygen saturation, postnatal comorbidities, or nutritional supplementation, in the WINROP algorithm. Some complications of prematurity, such as necrotizing enterocolitis, intraventricular hemorrhage, sepsis and hydrocephalus could induce excessive weight gain that would interfere with the algorithm's ability to detect infants at risk of severe ROP. ${ }^{13}$ By the other hand, WINROP alarm may be designed to be activated for small for gestational age infants and relatively high birth weights are more common in extremely preterm infants.

In our experience, the WINROP algorithm has proven to be a useful tool in predicting treatmentrequiring ROP. Even though the specificity and the PPV were relatively low, the $100 \%$ sensitivity and $100 \%$ NPV support the safety of using WINROP to reduce the number of stressful ophthalmic examinations. Nevertheless, special caution should be taken when using WINROP in extremely preterm infants (GA $<28$ weeks). Population-specific optimization and the inclusion of other postnatal factors are required to improve the algorithm results.

\section{CONCLUSIONS}

With $100 \%$ sensitivity $(\mathrm{Cl} 95 \%, 59-100)$ and $100 \%$ NPV (CI 95\%, 93.7-100), the WINROP algorithm has proven to be a safe non-invasive tool in identifying premature infants at risk of developing severe ROP. Similar results have been obtained in other developed countries, allowing to reduce the number of unnecessary stressful examinations during ROP screening. 


\section{REFERENCES}

1. Gilbert C, Fielder A, Gordillo L, Quinn G, Semiglia $R$, Visintin $P$, et al. Characteristics of infants with severe retinopathy of prematurity in countries with low, moderate, and high levels of development: implications for screening programs. Pediatrics. 2005 May;115(5):e518-25.

2. Hartnett ME. Pathophysiology and mechanisms of severe retinopathy of prematurity. Ophthalmology. 2015 Jan;122(1):200-10.

3. Fierson WM. Screening examination of premature infants for retinopathy of prematurity. Pediatrics. 2013 Jan;131(1):189-95.

4. Revised indications for the treatment of retinopathy of prematurity: results of the early treatment for retinopathy of prematurity randomized trial. Arch Ophthalmol (Chicago, III 1960). 2003 Dec;121(12):1684-94.

5. Kandasamy $Y$, Smith $R$, Wright IMR, Hartley L. Pain relief for premature infants during ophthalmology assessment. J AAPOS Off Publ Am Assoc Pediatr Ophthalmol Strabismus. 2011 Jun;15(3):276-80.

6. Engstrom E, Niklasson A, Wikland KA, Ewald U, Hellstrom A. The role of maternal factors, postnatal nutrition, weight gain, and gender in regulation of serum IGF-I among preterm infants. Pediatr Res. 2005 Apr;57(4):605-10.

7. de Jong $M$, Cranendonk $A$, Twisk JWR, van Weissenbruch MM. IGF-I and relation to growth in infancy and early childhood in very-low-birthweight infants and term born infants. PLoS One. 2017;12(2):e0171650.

8. Darlow BA, Binenbaum G. Oxygen, weight gain, IGF-1 and ROP: not a straight-forward equation. Vol. 107, Acta paediatrica (Oslo, Norway: 1992). Norway; 2018. p. 732-3.

9. Lofqvist $C$, Andersson E, Sigurdsson J, Engstrom E, Hard A-L, Niklasson A, et al. Longitudinal postnatal weight and insulin-like growth factor I measurements in the prediction of retinopathy of prematurity. Arch Ophthalmol (Chicago, III 1960). 2006 Dec;124(12):1711-8.

10. Hellstrom A, Hard A-L, Engstrom E, Niklasson $A$, Andersson $E$, Smith $L$, et al. Early weight gain predicts retinopathy in preterm infants: new simple, efficient approach to screening. Pediatrics. 2009 Apr;123(4):e638-45.

11. Eriksson L, Liden U, Lofqvist C, Hellstrom A. WINROP can modify ROP screening praxis: a validation of WINROP in populations in Sormland and Vastmanland. Br J Ophthalmol. 2014 Jul;98(7):964-6.

12. Hard A-L, Lofquist C, Fortes Filho JB, Procianoy RS, Smith L, Hellstrom A. Predicting proliferative retinopathy in a Brazilian population of preterm infants with the screening algorithm WINROP. Arch Ophthalmol (Chicago, III 1960). 2010 Nov;128(11):1432-6.

13. Choi J-H, Lofqvist $\mathrm{C}$, Hellstrom A, Heo H. Efficacy of the screening algorithm WINROP in a Korean population of preterm infants. JAMA Ophthalmol. 2013 Jan;131(1):62-6.

14. The International Classification of Retinopathy of Prematurity revisited. Arch Ophthalmol (Chicago, III 1960). 2005 Jul;123(7):991-9.

15. Good W V. Final results of the Early Treatment for Retinopathy of Prematurity (ETROP) randomized trial. Trans Am Ophthalmol Soc. 2004;102:233-50.

16. Holmström G, Hellström A, Gränse $L$, Saric $M$, Sunnqvist $B$, Wallin $A$, et al. New modifications of Swedish ROP guidelines based on 10-year data from the SWEDROP register. $\mathrm{Br} J$ Ophthalmol. 2019 Nov;

17. Khorshidifar M, Nikkhah $H$, Ramezani A, Entezari $M$, Daftarian $N$, Norouzi $H$, et al. Incidence and risk factors of retinopathy of prematurity and utility of the national screening criteria in a tertiary center in Iran. Int J Ophthalmol. 2019;12(8):1330-6. 
18. Quinn GE, Ying G-S, Bell EF, Donohue PK, Morrison D, Tomlinson LA, et al. Incidence and Early Course of Retinopathy of Prematurity: Secondary Analysis of the Postnatal Growth and Retinopathy of Prematurity (G-ROP) Study. JAMA Ophthalmol. 2018 Dec;136(12):1383-9.

19. Bas AY, Demirel $N$, Koc $E$, Ulubas Isik $D$, Hirfanoglu IM, Tunc T. Incidence, risk factors and severity of retinopathy of prematurity in Turkey (TR-ROP study): a prospective, multicentre study in 69 neonatal intensive care units. $\mathrm{Br} \mathrm{J}$ Ophthalmol. 2018 Dec;102(12):1711-6.

20. Gerull R, Brauer V, Bassler D, Laubscher B, Pfister $R E$, Nelle $M$, et al. Incidence of retinopathy of prematurity (ROP) and ROP treatment in Switzerland 2006-2015: a population-based analysis. Arch Dis Child Fetal Neonatal Ed. 2018 Jul;103(4):F337-42.

21. Lofqvist C, Hansen-Pupp I, Andersson E, Holm K, Smith LEH, Ley $D$, et al. Validation of a new retinopathy of prematurity screening method monitoring longitudinal postnatal weight and insulinlike growth factor I. Arch Ophthalmol (Chicago, III 1960). 2009 May;127(5):622-7.

22. Wu C, Vanderveen DK, Hellstrom A, Lofquist $C$, Smith LEH. Longitudinal postnatal weight measurements for the prediction of retinopathy of prematurity. Arch Ophthalmol (Chicago, III 1960). 2010 Apr;128(4):443-7.

23. Timkovic J, Pokryvkova M, Janurova K, Barinova $D$, Polackova R, Masek P. Evaluation of the WinROP system for identifying retinopathy of prematurity in Czech preterm infants. Biomed Pap Med Fac Univ Palacky Olomouc Czech Repub. 2017 Mar;161(1):111-6.

24. Wu C, Lofqvist C, Smith LEH, VanderVeen DK, Hellstrom A. Importance of early postnatal weight gain for normal retinal angiogenesis in very preterm infants: a multicenter study analyzing weight velocity deviations for the prediction of retinopathy of prematurity. Arch
Ophthalmol (Chicago, III 1960). 2012 Aug;130(8):992-9.

25. Zepeda-Romero LC, Hard A-L, Gomez-Ruiz LM, Gutierrez-Padilla JA, Angulo-Castellanos E, Barrera-de-Leon $J C$, et al. Prediction of retinopathy of prematurity using the screening algorithm WINROP in a Mexican population of preterm infants. Arch Ophthalmol (Chicago, III 1960). 2012 Jun; 130(6):720-3.

26. Sun $H$, Kang $W$, Cheng $X$, Chen $C$, Xiong $H$, Guo $J$, et al. The use of the WINROP screening algorithm for the prediction of retinopathy of prematurity in a Chinese population. Neonatology. 2013;104(2):127-32.

27. Lundgren $P$, Stoltz Sjostrom $E$, Domellof $M$, Kallen K, Holmstrom G, Hard A-L, et al. WINROP identifies severe retinopathy of prematurity at an early stage in a nation-based cohort of extremely preterm infants. PLoS One. 2013;8(9):e73256.

28. Piyasena $C$, Dhaliwal $C$, Russell $H$, Hellstrom $A$, Lofqvist $C$, Stenson BJ, et al. Prediction of severe retinopathy of prematurity using the WINROP algorithm in a birth cohort in South East Scotland. Arch Dis Child Fetal Neonatal Ed. 2014 Jan;99(1):F29-33.

29. Ko C-H, Kuo H-K, Chen C-C, Chen F-S, Chen Y$\mathrm{H}$, Huang $\mathrm{H}-\mathrm{C}$, et al. Using WINROP as an adjuvant screening tool for retinopathy of prematurity in southern Taiwan. Am J Perinatol. 2015 Feb;30(2):149-54.

30. Kocak N, Niyaz L, Ariturk N. Prediction of severe retinopathy of prematurity using the screening algorithm WINROP in preterm infants. J AAPOS Off Publ Am Assoc Pediatr Ophthalmol Strabismus. 2016 Dec;20(6):486-9.

31. Sanghi G, Narang A, Narula $S$, Dogra MR. WINROP algorithm for prediction of sight threatening retinopathy of prematurity: Initial experience in Indian preterm infants. Indian J Ophthalmol. 2018 Jan;66(1):110-3. 
32. Lundgren $P$, Stoltz Sjöström $E$, Domellöf $M$, Smith L, Wu C, VanderVeen D, et al. The Specificity of the WINROP Algorithm Can Be Significantly Increased by Reassessment of the WINROP Alarm. Neonatology. 2015;108(2):1526.

33. Jung JL, Wagner BD, McCourt EA, Palestine AG, Cerda $\mathrm{A}, \mathrm{Cao} \mathrm{JH}$, et al. Validation of WINROP for detecting retinopathy of prematurity in a North American cohort of preterm infants. J AAPOS Off Publ Am Assoc Pediatr Ophthalmol Strabismus. 2017 Jun;21(3):229-33.

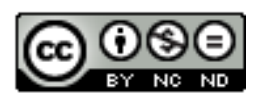

This work licensed under Creative Commons Attribution 